\title{
Relação entre conhecimento explícito da ortografia e desempenho ortográfico
}

\author{
Maria José dos Santos \\ Sylvia Domingos Barrera
}

\section{Resumo}

Aprender a escrever demanda, além do domínio do sistema alfabético, aprendizagem da ortografia. Apesar do caráter convencional e reprodutivo das regras ortográficas, é reconhecido que a apropriação dessas não é um processo passivo. Pesquisas sugerem que o desempenho ortográfico varia em função do nível de elaboração das representações ortográficas do aprendiz. Neste estudo investigamos a relação entre desempenho ortográfico e nível de explicitação do conhecimento ortográfico de 22 crianças da $4^{a}$ série do Ensino Fundamental. Estas realizaram três atividades: ditado de frases, escrita com violação proposital da ortografia e entrevista. Os resultados mostram relação entre desempenho ortográfico e natureza da violação da ortografia. As crianças com melhor desempenho ortográfico violaram a ortografia de forma a não alterar a fonologia das palavras, demonstrando também maior conhecimento explícito das regras ortográficas. Esses dados sugerem a importância de introduzir no ensino da escrita atividades que favoreçam a reflexão sobre a ortografia.

Palavras-chave: Ortografia, escrita, metacognição.

\section{Relationship between explicit spelling knowledge and spelling performance}

\begin{abstract}
Learning writing demands, beyond the domain of the alphabetic system, learning spelling. Despite the conventional and reproductive character of orthographic rules, it is recognized that their appropriation isn't a passive process. Research suggests that the spelling performance depends on the level of elaboration of learner's orthographic representations. We investigated the relationship between spelling performance and level of explicit knowledge of the orthographic rules of 22 students of the $4^{\text {th }}$ grade of elementary school. Students performed three activities: sentence writing, words writing with deliberate violation of spelling and interview. The results show the relationship between spelling performance and natures of the violation of spelling. Children with better spelling performance violated the orthography without altering the phonology of words, demonstrating greater explicit knowledge of orthographic rules. These data suggest the importance of teaching writing activities that encourage the explicit reflection on spelling.
\end{abstract}

Key-words: Ortography, handwriting, metacognition.

\section{Relación entre conocimiento explícito de la ortografía y rendimiento ortográfico}

\section{Resumen}

Aprender a escribir requiere además del dominio del sistema alfabético aprendizaje de la ortografía. A pesar del carácter convencional y repetitivo de las reglas ortográficas se reconoce que su apropiación no se trata de un proceso pasivo. Investigaciones sugieren que el rendimiento ortográfico varía de acuerdo con el nivel de elaboración de las representaciones ortográficas del aprendiz. En el presente estudio investigamos la relación entre rendimiento ortográfico y el nivel de explicitación del conocimiento ortográfico de 22 niños del $4^{\circ}$ año de Enseñanza Básica. Realizaron tres actividades: dictado de frases, escritura con violación deliberada de ortografía y entrevista. Los resultados muestran relación entre rendimiento ortográfico y naturaleza de la violación de ortografía. Los niños con mejor rendimiento ortográfico violaron la ortografía de forma a no alterar la fonología de las palabras demostrando también mayor conocimiento explícito de las reglas ortográficas. Estos datos sugieren la importancia de introducir en la enseñanza de la escritura actividades que favorezcan la reflexión sobre la ortografía.

Palabras clave: Ortografía, escritura, metacognición. 


\section{Introdução}

A capacidade de se comunicar por meio da língua escrita é considerada, na sociedade contemporânea, uma importante ferramenta para a aquisição de conhecimentos e condição básica para o sucesso escolar. Conforme apontam Horta e Martins (2004), um dos componentes da escrita é a ortografia, definida "como a codificação das formas linguísticas em formas escritas, respeitando um contrato social aceite e respeitado por todos" (p.213).

A definição oferecida pelas autoras acima citadas revela o caráter convencional da ortografia, ditado pelo costume e etimologia das palavras, pelo uso e evolução histórica. A ortografia reflete, por conseguinte, a história e a cultura da língua que representa (Morais \& Teberosky, 1994). É, portanto, um tipo de saber que resulta de uma convenção, de uma negociação social e acadêmica e que, em última instância, tem um caráter normativo e prescritivo.

Tal caráter normativo e prescritivo denuncia, de um lado, a natureza arbitrária da norma ortográfica, ou seja, esta não possui nenhuma razão de obrigatoriedade, e, por outro lado, sua finalidade, qual seja, a de facilitar a comunicação entre os leitores de uma mesma língua. Por maior que seja a variedade linguística usada pelos falantes e por mais que essa variedade revele a riqueza cultural da língua, a ortografia garante que qualquer leitor reconheça uma dada palavra escrita (Cagliari, 1992; Morais, 2009).

A ortografia é um aspecto bastante valorizado pela sociedade, pois se entende que, por mais organizado e aprimorado que esteja um texto, caso contenha erros ortográficos, seu êxito como instrumento de comunicação é improvável. No mundo contemporâneo, cada vez mais, temos que usar a leitura e a escrita como instrumentos sociais e a correção da escrita torna-se aspecto fundamental na comunicação.

Morais (2009), ao analisar a ortografia do português, faz uma distinção entre ortografias regulares e irregulares. Classifica como regulares aquelas ortografias cujas regras subjacentes são passíveis de compreensão e irregulares aquelas formas ortográficas cujo uso é justificado pela tradição ou pela etimologia das palavras. Nesses casos, não havendo regra, a ortografia correta da palavra precisa ser memorizada.

Segundo Morais (2009), haveria três tipos de relações regulares entre letras e sons: diretas, contextuais e morfológico-gramaticais. Nas relações regulares diretas, cada letra corresponde a um único som, e cada som é representado por uma única letra, o que caracteriza uma regularidade absoluta entre letra e som. Nessa categoria estão as letras $<\mathrm{P}, \mathrm{B}, \mathrm{T}, \mathrm{D}, \mathrm{V}, \mathrm{F}>$, como, por exemplo, nas palavras "tapa", "gatata" e "matagal", em que o fonema /t/ é representado sempre pela letra $T$, independente da posição que ocupe na palavra. Nesse tipo de relação regular direta entre som e letra, qualquer alteração ortográfica compromete a leitura da palavra: na palavra "pato", a troca do P pelo B altera sua leitura e transforma o significado da palavra (pato/bato).

Nas relações regulares entre letra e som de tipo contextual, o contexto do interior da palavra define a utilização das letras. Por exemplo, a utilização de R ou RR é definida em função do contexto em que aparece a letra/som: para registrar o "R forte" usamos $\mathrm{R}$ no início da palavra (rosa), no começo de sílabas precedidas por consoante (honra) e no final de sílabas (gorda). Nesses casos a alteração ortográfica não compromete a leitura da palavra, tampouco transforma o significado da palavra (rrosa; honrra; gorrda). Nos casos em que o "R forte" aparece entre vogais (morro), utiliza-se RR. A ortografia do português inclui muitos casos de regularidades ortográficas de tipo contextual; nesses casos, a ortografia não precisa ser memorizada, é possível prevê-la levando em conta o contexto, ou seja, a posição que a letra ocupa na palavra (Morais, 2009).

Nas relações entre letras e sons motivadas por questões morfossintáticas, os aspectos morfológicos e a categoria gramatical da palavra definem as regras ortográficas. Assim, escolher o sufixo ESA ou EZA depende de uma análise gramatical da palavra: sendo a palavra um adjetivo derivado de substantivo, o sufixo será escrito com S (portuguesa ou baronesa); sendo a palavra um substantivo derivado de um adjetivo, o sufixo será escrito com Z, como em "beleza" e "gentileza" (Morais, 2009). Alterações ortográficas por substituição de S por Z não alteram a leitura da palavra nem o seu significado.

Finalmente, a categoria de ortografias irregulares diz respeito às formas ortográficas que não têm uma regra que as justifique. A forma ortográfica é definida por tradição ou pela etimologia da palavra. Nessa categoria encontram-se a escrita de palavras com "som do S", "som do Z", "som do G" e "som do X", e incluem-se também o emprego do $\mathrm{H}$ inicial em algumas palavras; o emprego da letra E ou I (cigarro/ seguro); o emprego da letra $\mathrm{O}$ ou $U$ (bonito/tamborim); o emprego do L ou LH (Júlio/julho) e a escrita de ditongos que têm a pronúncia reduzida (como em caixa e madeira). No caso das ortografias irregulares, não há o que compreender: a aprendizagem requer memorização (Morais, 2009). Nesses casos também temos muitas alterações ortográficas que não alteram a leitura da palavra, como no caso de casa/ caza; homem/omem; seguro/siguru etc.

Dada a complexidade do nosso sistema de escrita, a tarefa do aprendiz da ortografia é também complexa e exige apropriar-se de regras que não são de mesma natureza e, portanto, sua aquisição requer diferentes competências.

As pesquisas acerca da aprendizagem da ortografia podem, de maneira geral, ser divididas em três grupos: (1) aquelas que avaliam os tipos de erros e descrevem o desempenho ortográfico; (2) aquelas que investigam a relação entre competências cognitivas e aprendizagem de aspectos ortográficos específicos; (3) aquelas que estudam o processo de aquisição de aspectos ortográficos específicos.

Os estudos que analisam os tipos de erros ortográficos e descrevem o desempenho ortográfico sugerem uma apropriação progressiva do sistema ortográfico de escrita. Os erros cometidos pelas crianças refletiriam o nível de elaboração sobre o conhecimento ortográfico, sendo, portanto, considerados tentativas de grafar as palavras com base nos conhecimentos ortográficos alcançados (Carraher, 1985; Nobile \& Barrera, 2009; Nunes, 1992; Zorzi, 1998, 2003). 
As pesquisas que buscam compreender os processos de aquisição de aspectos ortográficos específicos mostram que, embora algumas regras ortográficas tenham a mesma natureza, as crianças não as adquirem simultaneamente. Mesmo as regras que são gramaticalmente semelhantes (como, por exemplo, registrar <e > e <0> nas sílabas átonas no final de palavras, mesmo que a pronúncia seja /i/ e /u/) não são aprendidas concomitantemente, ou seja, não há uma aprendizagem conjunta de regras semelhantes, tampouco subordinação entre elas. As investigações da aprendizagem deste e de outros contextos ortográficos mostram um percurso comum na aquisição de aspectos ortográficos: inicialmente a criança registra as palavras como são pronunciadas segundo as correspondências grafofônicas regulares aprendidas. O contato com outros contextos ortográficos possibilita que a criança faça reestruturações de suas hipóteses, compreendendo de maneira mais elaborada as restrições ortográficas impostas pelo português (Meireles \& Correa, 2006; Monteiro, 2005; Nunes, 1992; Rego \& Buarque, 1997).

As investigações acerca da relação entre competências cognitivas e aprendizagem de aspectos ortográficos mostram que o conhecimento metalinguístico é fundamental na apropriação da ortografia. A consciência fonológica, ou seja, a habilidade para refletir sobre o aspecto sonoro da língua estaria relacionada com a aprendizagem das regularidades ortográficas diretas e contextuais, e a consciência morfossintática parece estar associada à escrita correta de palavras cuja grafia requer conhecimento e compreensão de aspectos morfológicos e sintáticos da língua (Guimarães \& Roazzi, 2005; Leal \& Roazzi, 2005; Paula, Miranda, Mota, \& Justi, 2009; Rego \& Buarque, 1997; Silva, 2010).

Ao estudar o tema do desenvolvimento metalinguístico na criança, Maluf e Gombert (2008) consideram a interação entre dois tipos de conhecimentos sobre a linguagem: os conhecimentos implícitos (também chamados por eles de epilinguísticos), os quais se desenvolvem de forma espontânea e precoce, e os conhecimentos explícitos, ou propriamente metalinguísticos, que envolvem a reflexão e o controle intencional sobre diversos aspectos da língua oral. As capacidades metalinguísticas, portanto, repousam sobre conhecimentos linguísticos explícitos, mentalizados e intencionalmente aplicados, que aparecem geralmente na idade escolar e sob influência do ensino da linguagem escrita, quando as crianças se mostram capazes, entre outras coisas, de corrigir (e justificar) a sintaxe ou a ortografia de um texto, por exemplo.

Estudos sobre a relação entre conhecimento explícito da ortografia e desempenho em tarefas de escrita sugerem que o desempenho ortográfico em tarefas de escrita está relacionado com o nível de explicitação dos conhecimentos sobre a norma ortográfica. Esses estudos têm usado como instrumento metodológico a tarefa de "escrever errado de propósito" ou tarefa de transgressões intencionais. Nessa tarefa a criança é solicitada a reescrever palavras cometendo erros ortográficos propositadamente. Baseada no modelo de redescrição representacional (Karmiloff-Smith, 1986), a tarefa parte do princípio de que, para cometer erros intencionais, a criança necessitaria ter domínio explícito da norma ortográfica. Have- ria, no início da aprendizagem da ortografia, apenas um nível implícito do conhecimento ortográfico. O domínio e a compreensão dos princípios subjacentes às normas ortográficas, por parte da criança, possibilitariam um nível mais explícito de elaboração do conhecimento, de forma que a criança não só aplicaria seu conhecimento, mas também seria capaz de explicar o conhecimento utilizado na geração de grafias (Morais, 1996, 2005b, 2009; Morais \& Teberosky, 1994; Santos \& Maluf, 2006; Santos, Rosa, \& Nicolau, 2009). Há evidências de que a capacidade da tarefa de transgressão intencional em discriminar o bom desempenho ortográfico está relacionada à natureza da regra ortográfica e sua dificuldade. Dessa forma, a tarefa de transgressão intencional seria preditora do desempenho ortográfico nos contextos ortográficos problemáticos para a criança, ou seja, nos contextos cuja dificuldade a criança tem consciência (Meireles \& Correa, 2006).

Inserindo-se nessa última abordagem dos estudos sobre a aprendizagem da ortografia, o presente estudo teve como objetivo investigar a relação entre desempenho ortográfico, qualidade das transgressões intencionais e grau de explicitação das mesmas. Pretendemos examinar se as crianças com bom desempenho ortográfico cometiam violações ortográficas mais sofisticadas do que aquelas que apresentavam fraco desempenho ortográfico. Duas hipóteses nortearam a presente pesquisa: 1) a hipótese de que as crianças com bom desempenho ortográfico, ao serem solicitadas a transgredirem intencionalmente a ortografia, o fariam sem alterar a fonologia da palavra, ou seja, sem alterar as regras do sistema alfabético de escrita, violando assim apenas as normas ortográficas; 2) a hipótese de que as crianças com bom desempenho ortográfico teriam mais facilidade em explicitar verbalmente as regras ortográficas transgredidas na tarefa de violação ortográfica.

\section{Método}

\section{Participantes}

Participaram da pesquisa 22 crianças da $4^{\mathrm{a}}$ série do Ensino Fundamental, com idades entre nove e 11 anos, idade média de 10 anos e 3 meses, que frequentavam uma escola pública no Estado de Goiás.

\section{Procedimentos}

Os alunos realizaram três tarefas: (1) escrita sob ditado; (2) escrita com transgressão intencional e (3) entrevista. Tarefa de escrita sob ditado: As crianças foram solicitadas a escrever, sob ditado, um texto composto por 20 frases e 144 palavras (Zanella, 2010). No ditado, feito pela própria pesquisadora, as palavras foram lidas de forma corrente, na forma mais próxima possível da linguagem oral do cotidiano, sem artificialização da pronúncia. Essa tarefa foi de aplicação coletiva. 
O ditado foi analisado considerando-se o número de erros cometidos em cada palavra. A cada erro foi atribuído 1 ponto.

Tarefa de reescrita de palavras com violação intencional: As crianças receberam um protocolo com 23 palavras escritas ortograficamente corretas, escolhidas entre aquelas usadas no ditado, e foram solicitadas a reescreverem as palavras cometendo erros ortográficos propositais (transgressões intencionais). Essa prova foi de aplicação individual.

As transgressões intencionais foram classificadas em três categorias: (1) transgressões por substituição de letras, (2) transgressões por omissão de letras e (3) transgressões por adição de letras.

Entrevista: As crianças foram solicitadas a justificar as transgressões cometidas na reescrita de palavras. As entrevistas foram gravadas em áudio e posteriormente transcritas.

As respostas foram analisadas qualitativamente, com base no grau de explicitação das normas ortográficas violadas.

\section{Resultados}

Inicialmente foi feita uma análise do desempenho ortográfico das crianças na tarefa de escrita sob ditado. O Quadro 1 apresenta o número de erros ortográficos cometidos pelas crianças investigadas.
A partir dessa análise e do cálculo da mediana (Md) e dos quartis (Q1 e Q3), identificamos as seis crianças que cometeram menos erros ortográficos, portanto com melhor desempenho (G1: pontuação = Q1) e as seis crianças que cometeram maior número de erros ortográficos, portanto com pior desempenho ortográfico (G2: pontuação = Q3).

O G1 foi composto pelas crianças 2, 3, 15, 17, 18 e 19, que, juntas, cometeram 53 erros no ditado. O G2 foi composto pelas crianças 7, 8, 10, 11, 12 e 13, que, somados os erros, cometeram 362 erros.

$\mathrm{Na}$ análise da tarefa de reescrita de palavras com transgressão intencional, as transgressões foram classificadas em: (1) Transgressões por substituição de letras (TS), (2) Transgressões por omissão de letras (TO) e (3) Transgressões por adição de letras (TAd). O resultado está na Tabela 1.

Como é possível observar, as crianças do G1 cometeram 171 transgressões, sendo 114 por substituição de letras, 55 por omissão de letras e duas por adição de letras. As crianças do G2 cometeram 218 transgressões, sendo 162 por substituição de letras, 45 por omissão de letras e 11 por adição de letras.

Analisamos as transgressões, considerando alterações na fonologia da palavra: transgressões que ferem a fonologia da palavra (TF) e transgressões que não ferem a fonologia da palavra (TNF). A Tabela 2 mostra os resultados obtidos nessa análise.

Quadro 1. Frequência de erros ortográficos (E) produzidos pelas crianças (C) na tarefa de ditado.

\begin{tabular}{|l|l|l|l|l|l|l|l|l|l|l|l|l|l|l|l|l|l|l|l|l|l|l|}
\hline $\mathrm{C}$ & 1 & 2 & 3 & 4 & 5 & 6 & 7 & 8 & 9 & 10 & 11 & 12 & 13 & 14 & 15 & 16 & 17 & 18 & 19 & 20 & 21 & 22 \\
\hline $\mathrm{E}$ & 22 & 9 & 8 & 50 & 33 & 25 & 53 & 67 & 39 & 60 & 56 & 51 & 75 & 23 & 6 & 26 & 12 & 7 & 11 & 26 & 31 & 23 \\
\hline
\end{tabular}

$\mathrm{Md}=26 ; \quad \mathrm{Q} 1=12 ; \quad \mathrm{Q} 3=51$

Tabela 1. Frequência e tipo de transgressões ortográficas intencionais realizadas pelos participantes.

\begin{tabular}{ccccc}
\hline Tipo de Transgressão & TS & To & TAd \\
Participantes & $\begin{array}{c}\text { (substituição de } \\
\text { letra) }\end{array}$ & $\begin{array}{c}\text { (omissão de letra) } \\
\text { (acréscimo } \\
\text { letra) }\end{array}$ & de & Total \\
\hline G1 & 114 & 55 & 2 & 171 \\
\hline $\begin{array}{c}\text { (melhor desempenho } \\
\text { ortográfico) }\end{array}$ & & & \\
\hline
\end{tabular}

G2

(pior desempenho

162

45

11

218

ortográfico) 
Tabela 2. Número e porcentagem de transgressões intencionais que ferem (TF) ou não ferem (TNF) a fonologia da palavra em cada subgrupo.

\begin{tabular}{|c|c|c|c|}
\hline Transgressões intencionais & & $\begin{array}{c}\text { G1 } \\
\text { (melhor desempenho } \\
\text { ortográfico) }\end{array}$ & $\begin{array}{l}\text { G2 } \\
\text { (pior desempenho } \\
\text { ortográfico) }\end{array}$ \\
\hline \multirow[t]{2}{*}{ TS (substituição de letra) } & TNF & $92(80,7 \%)$ & $56 \quad(34,3 \%)$ \\
\hline & TF & $22 \quad(19,3 \%)$ & $(65,7 \%)$ \\
\hline \multirow[t]{2}{*}{ TO (omissão de letra) } & TNF & $24 \quad(45,6 \%)$ & $(24,4 \%)$ \\
\hline & TF & $31 \quad(54,5 \%)$ & $34 \quad(75,6 \%)$ \\
\hline \multirow[t]{2}{*}{ TAd (acréscimo de letra) } & TNF & $01 \quad(50,0 \%)$ & $(0 \%)$ \\
\hline & TF & $01 \quad(50,0 \%)$ & $(100 \%)$ \\
\hline Total & & 171 & 218 \\
\hline
\end{tabular}

Como é possível observar, nos três tipos de transgressão (por substituição, por omissão e por adição de letras), as crianças do G1 realizaram, mais frequentemente que as crianças do $\mathrm{G} 2$, transgressões que não ferem a fonologia da palavra.

Aplicando-se o teste do Qui-quadrado aos dados obtidos para comparação das frequências de transgressões ortográficas realizadas pelos dois grupos, observa-se que a diferença entre as mesmas é significativamente maior do que a esperada ao acaso para as três categorias de transgressões consideradas. Isso indica que o G1, composto pelas crianças com melhor desempenho ortográfico, cometeu significativamente mais erros que não ferem a estrutura fonológica da palavra do que o $\mathrm{G} 2\left(X^{2}=57,26\right.$ com $p<0,01$ para as TS; $X^{2}=4,00$ com $p<0,05$ para as TO e $X^{2}=6,11$ com $\mathrm{p}<0,05$ para as TAd).

$\mathrm{Na}$ categoria de transgressões por substituição de letras (TS), 80,7\% das transgressões realizadas pelo G1 não alteraram a fonologia das palavras e apenas 19,3\% das transgressões alteraram a fonologia. Nessa categoria encontramos substituições de letras que podem representar vários sons, como, por exemplo, substituição de Z pelo S na palavra "beleza" (justificativa: "para escrever está errado, mas prá ler fica igual"); substituições de letras por apoio na oralidade, como, por exemplo, substituição de O por $U$, como na palavra "preferido" (justificativa: "a gente fala /preferidu/, mas escreve preferido"); substituição de M por N, como, por exemplo, na palavra "campo" (justificativa: porque tem a letra P, então tem que colocar $\mathrm{M}$, mas lê igual"). As justificativas dadas pelas crianças do G1 sugerem que elas têm maior domínio explícito das regras ortográficas e, portanto, são capazes de infringi-las, sem alteração no sistema alfabético de escrita.

Das transgressões por substituição de letras realizadas pelo $\mathrm{G} 2$, apenas $34,3 \%$ não alteraram a fonologia da palavra e $65,7 \%$ das transgressões realizadas feriram a fonologia, ou seja, infringiram o sistema alfabético de escrita, como, por exemplo, substituição da letra B por $\mathrm{P}$ na palavra "Morumbi" (justificativa: "eu troquei a letra B e escrevi com P"); substituição de F por V na palavra "preferido" (justificativa: "eu mudei uma letra"); substituição da letra E por I na palavra "beleza" (justificativa: "tirei o E e coloquei o I").

$\mathrm{Na}$ categoria de transgressões por omissão de letras (TO), as crianças do G1 cometeram 45,6\% transgressões que não alteraram a fonologia das palavras e $54,5 \%$ transgressões que alteraram a fonologia das palavras. A análise dos dados revela que $47,8 \%$ das omissões de letras referem-se às sílabas complexas, como no caso da palavra "melhor", em que foi omitida a letra $\mathrm{H}$, ou da palavra "preferido", em que foi omitida a letra R. Das transgressões realizadas pelas crianças do $\mathrm{G} 2$, apenas $24,4 \%$ não feriram a fonologia da palavra e $75,6 \%$ alteraram a pronúncia da palavra. Podemos citar como exemplo a omissão da letra M na palavra "melhor". Embora as crianças do G1 tenham tido um número grande de transgressões com alteração da fonologia da palavra, as transgressões realizadas são qualitativamente superiores quando comparadas às transgressões das crianças do G2. Por exemplo, a criança que omitiu o R na palavra "preferido", justificou a transgressão dizendo que há pessoas que falam /peferido/. A criança que omitiu a 
letra M na palavra "melhor" justificou a omissão dizendo que escrever dessa forma é errado.

Com relação à transgressão por adição de letras (TAd), as crianças do G1 cometeram apenas duas transgressões, sendo uma com alteração da fonologia da palavra e outra que não alterou sua fonologia. As crianças do G2 cometeram 11 transgressões por adição de letras, todas elas alterando a fonologia da palavra, como, por exemplo, nas palavras "laedeira" e "campeonatoa". Quando solicitadas a justificarem, disseram: "eu coloquei outra letra"; "aumentei uma letra prá ficar errado".

Assim, é possível afirmar que a maior parte das transgressões cometidas pelas crianças do G2 infringiram as regras do sistema alfabético e essas crianças não conseguiram justificar as transgressões feitas com base nas normas ortográficas. Por outro lado, a análise das entrevistas sugere que as crianças que são capazes de verbalizar explicitamente as regras ortográficas violadas apresentam um melhor desempenho ortográfico.

Violar as regras do sistema alfabético consiste em uma transgressão mais grosseira, uma vez que a criança só está considerando o sistema de notação alfabética, por exemplo, para a palavra "Morumbi", escrever "Morumpi". Nesse tipo de violação, a criança cometeu uma transgressão não apenas das normas ortográficas, mas das regras do sistema alfabético (fonema /b/ é grafado com a letra B). Do ponto de vista da evolução da aprendizagem, conhecer as regras do sistema alfabético e, portanto, poder violá-lo antecede a aprendizagem de outras regularidades ortográficas mais complexas.

\section{Discussão}

Nesta pesquisa tivemos por objetivo estudar a relação entre desempenho ortográfico e qualidade da transgressão intencional da norma ortográfica. Os resultados evidenciaram relação entre desempenho ortográfico, qualidade da transgressão e capacidade de explicitação das regras ortográficas. Esses resultados corroboram aqueles de pesquisas anteriores (Morais, 2005a; 2005b; Meireles \& Correa, 2006) e sugerem que o conhecimento explícito da norma ortográfica está relacionado com o desempenho ortográfico.

Os dados obtidos corroboram a ideia de que aprender a escrever ortograficamente é um processo complexo que não requer apenas o acúmulo de imagens de palavras corretas, ou seja, não basta o conhecimento implícito e não intencional, de natureza frequencial, que pode ser adquirido mediante atos de leitura, apoiando-se na frequência de ocorrência das palavras (cf. Maluf \& Gombert, 2008). Tampouco o conhecimento sobre a ortografia é algo a ser descoberto espontaneamente pela criança ou pelo aprendiz pela simples interação deste com a língua escrita. Tal aprendizagem necessita de um ensino sistemático e explícito de modo a levar o aluno a uma reflexão sobre as restrições ortográficas da língua escrita, estimulando-o a explicitar seus conhecimentos num nível consciente, desenvolvendo assim habilidades propriamente metalinguísticas a respeito da ortografia, fundamentadas em conhecimentos fonológico-contextuais e morfossintáticos.

Consideramos, portanto, que conhecer o processo de aprendizagem através do qual a criança se apropria do sistema ortográfico poderá favorecer a elaboração de estratégias didáticas que facilitem o ensino das regularidades e irregularidades do nosso sistema ortográfico.

Nos últimos anos, no Brasil, tem havido muitos avanços nas práticas pedagógicas da alfabetização, entretanto reconhecemos que maior prioridade foi dada ao letramento ou alfabetismo e pouco foi feito em relação aos aspectos relativos ao ensino da ortografia. Mudanças nas práticas de ensino da ortografia exigem uma melhor compreensão dos processos de aprendizagem e para isso é essencial o desenvolvimento de pesquisas e estudos que tenham como foco a aprendizagem da ortografia.

O ensino da ortografia, numa perspectiva que leve à reflexão, certamente favorecerá a formação de leitores e produtores de texto, bem como contribuirá para democratizar o acesso ao mundo da escrita.

\section{Referências}

Carraher, T. N. (1985). Explorações sobre o desenvolvimento da competência em ortografia em português. Psicologia: teoria e pesquisa, 1, 269-285.

Cagliari, L. C. (1992). Alfabetização e Lingüística (5a ed.). São Paulo: Scipione.

Guimarães, G., \& Roazzi, A. (2005). A importância do significado na aquisição da escrita ortográfica. Em A. G. Morais (Org.), O aprendizado da ortografia (pp.61-75). Belo Horizonte: Autêntica.

Horta, I. V., \& Martins, M. A. (2004). Desenvolvimento e aprendizagem da ortografia: implicações educacionais. Análise Psicológica, 22, 213-223.

Karmiloff-Smith, A. (1986). From meta-processes to conscious access: evidence from children's metalinguistic and repair data. Cognition, 23(2), 95-147.

Leal, T. F., \& Roazzi, A. (2005). A criança pensa... e aprende ortografia Em: A. G. Morais (Org.), O aprendizado da ortografia (pp. 99-120). Belo Horizonte: Autêntica.

Maluf, M. R., \& Gombert, J. E. (2008). Habilidades implícitas e controle cognitivo na aprendizagem da linguagem escrita. Em: M. R. Maluf \& S.R. K. Guimarães (Orgs.), Desenvolvimento da linguagem oral e escrita (pp. 123-135). Curitiba: Editora UFPR.

Meireles, E., \& Correa, J. (2006). A relação da tarefa de erro intencional com o desempenho ortográfico da criança considerados os aspectos morfossintáticos e contextuais da língua portuguesa. Estudos de Psicologia, 11, 35-43. 
Monteiro, A. M. L. (2005). "Sebra - ssono - pessado - asado" - O uso do "S" sob a ótica daquele que aprende. Em A. G. Morais (Org.), O aprendizado da ortografia (pp. 43-60). Belo Horizonte: Autêntica.

Morais, A. G. (1996). Escrever como deve ser. Em A. Teberosky \& L. Tolchinsky (Orgs.), Além da alfabetização (pp. 61-83). São Paulo: Ática.

Morais, A. G. (2005a). O Aprendizado da ortografia nas séries iniciais: evidências de pesquisa psicológica e ação didática. Recuperado: 15 de set 2006. Disponível: www.educacaoonline.pro.br

Morais, A. G. (2005b). Ortografia: este peculiar objeto de conhecimento. Em A. G. de Morais (Org.), O aprendizado da ortografia (pp. 7-19). Belo Horizonte: Autêntica.

Morais, A. G. (2009). Ortografia: ensinar e aprender (10a ed.). São Paulo: Ática.

Morais, A. G., \& Teberosky, A. (1994). Erros e transgressões infantis na ortografia do português. Discursos, 8, 15-51.

Nobile, G. G., \& Barrera, S. D. (2009). Análise de erros ortográficos em alunos do ensino público fundamental que apresentam dificuldades na escrita. Psicologia em Revista, 15, 36-55.

Nunes, T. (1992). Leitura e Escrita: processos e desenvolvimento. Em E. S. Alencar (Org.), Novas contribuições da psicologia aos processos de ensino e aprendizagem (pp. 13-50). São Paulo: Cortez.

Paula, F. V., Miranda, L. C., Mota, M., \& Justi, C. (2009). Consciência Morfológica do Português do Brasil: Relações com o Desenvolvimento Metalinguístico e a Alfabetização. Anais do IX Congresso Nacional de Psicologia Escolar e Educacional.
Rego, L. L. B., \& Buarque, L. L. (1997). Consciência sintática, consciência fonológica e aquisição de regras ortográficas. Psicologia: reflexão e crítica, 2, 199-217.

Santos, M. J., \& Maluf, M. R. (2006). Conhecimento explícito da norma ortográfica do português: um estudo com crianças de $4^{\mathrm{a}}$ série do ensino fundamental. Anais do II Congresso Brasileiro Psicologia: Ciência e Profissão. Recuperado: 3 nov 2006. Disponível: www. cienciaeprofissao.com.br/anais.cfm

Santos, M. J, Rosa, M. N., \& Nicolau, A. P. (2009). Ortografia: ensino e aprendizagem. Poíesis Pedagógica, 7, 109-129.

Silva, A. C. (2010). Consciência fonológica e morfológica e a natureza dos erros ortográficos em crianças do segundo ano de escolaridade com e sem dificuldades de aprendizagem. Actas do VII Simpósio Nacional de Investigação em Psicologia (Universidade do Minho/ Portugal), 2693-2703.

Zanella, M. S. (2010). Ortografia no ensino fundamental: um estudo sobre as dificuldades no processo de aprendizagem da escrita. Poíesis Pedagógica, 8, 109-125.

Zorzi, J. L. (1998). Aprender a escrever: a apropriação do sistema ortográfico. Porto Alegre: Artmed.

Zorzi, J. L. (2003). Aprendizagem e distúrbios da linguagem escrita: questões clínicas e educacionais. Porto Alegre: Artmed.

\section{Sobre as autoras}

Maria José dos Santos (majossantos@hotmail.com)

Doutora em Psicologia da Educação, Professora de Psicologia da Educação no Campus Catalão/UFG

Endereço: Rua 2, 199, Bairro J. K. CEP: 75709-310

Sylvia Domingos Barrera (sdbarrera@ffclrp.usp.br)

Doutora em Psicologia Escolar e do Desenvolvimento Humano, Professora do Departamento de Psicologia da FFCLRP/USP

Endereço: Av. dos Bandeirantes, 3.900 - CEP: 14040-901 - Ribeirão Preto / SP 